\title{
Editorial
}

\section{New directions in anticoagulant and antiplatelet treatment}

The advent of two new classes of drugs, the thrombin inhibitors and the IIB/IIIa platelet receptor blockers, may lead to major changes in anticoagulation practice the coming decade. We review the currently available data from clinical studies and speculate on how these classes of drugs may come to be used in clinical practice, bearing in mind that the benefits of these classes of drugs have not yet been determined precisely.

\section{Thrombin inhibitors}

The development of a thrombus, initiated by the formation of thrombin as the final stage of the coagulation cascade, is the major triggering mechanism in many acute ischaemic syndromes. ${ }^{12}$ Thrombin formation has three major effects:

- Generation of more thrombin through a positive feedback loop

- Formation of fibrin

- Activation of thrombocytes leading to aggregation and release of various vasoconstrictive and procoagulant factors.

Specific thrombin inhibitors block these effects, thus preventing or reducing both fibrin formation and thrombocyte aggregation (figure). The new generation of thrombin inhibitors include direct derivatives of hirudin, isolated from the leech Hirudo medicinalis, such as recombinant hirudin (a 65 amino acid polypeptide) and hirulog (a 20 amino acid peptide) as well as other synthetic compounds, including hirugen, argatroban, and efegatran. ${ }^{3-5}$

Though the thrombin inhibitors are often compared to heparin and like heparin can be given intravenously or subcutaneously, their mechanism of action is quite differ-

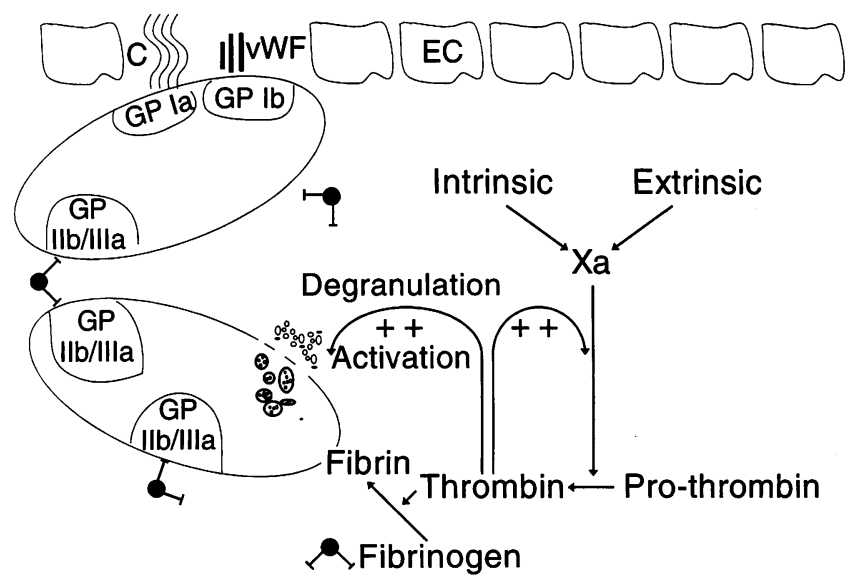

Thrombus development at the site of the damaged vascular wall (EC, endothelial cell) and the role of thrombin and the IIb/IILA receptor. Activation of factor $X$ induces thrombin formation in three major ways: formation of fibrin, generation of more fibrin through positive feedback, and activation of thrombocytes. Platelet membrane receptors include the glycoprotein (GP) Ia receptor binding to collagen $(C), G P I b$ to von Willebrand factor (vWF), and GP IIb/IILA which binds to different macromolecules including fibrinogen ent. Heparin inhibits thrombin formation, but its pharmacological activity is less specific than that of these new drugs. Among other factors, heparin requires antithrombin III, and it cannot inactivate clot-bound thrombin. Heparin can be inactivated by plasma proteins and platelet factor 4 , and it has other effects in addition to its anticoagulant properties, including inhibition of platelet function and inhibition of proliferation of vascular smooth muscle cells. ${ }^{6}$ In contrast, the new compounds are specific direct inhibitors of both free and clot-bound thrombin.

Heparin can be neutralised with protamine sulphate, but as yet the specific thrombin inhibitors have no antidote. Accordingly, this new class of drugs may be less suitable when the anticoagulation effect needs to be rapidly reversed-for example, during cardiac surgery. Nevertheless, the longest acting thrombin inhibitors have a half life of no more than a few hours, and when the infusion of the drug is stopped normal coagulation is quickly restored.

It is not certain how the optimal dose of specific thrombin inhibitors should be determined. Heparin dosing is adjusted according to measurement of activated partial thromboplastin time (aPTT) or activated clotting time (ACT). The thrombin inhibitors also prolong these indices in a steep, dose dependent manner, that could result in high levels of anticoagulation after even a small increase in dose. ${ }^{7-10} \mathrm{We}$ do not know whether the same prolongation of aPTT or ACT in patients treated with antithrombins represents the same level of anticoagulation and clinical efficacy as when they are treated with heparin. More data are needed to establish the relation between the desired clinical effects and the laboratory indices. No significant side effects were seen in 291 patients undergoing angioplasty who were treated with four different doses of hirulog, and there were no bleeding complications even at the highest dosage. ${ }^{11}$ In direct comparative trials of heparin and recombinant hirudin in patients undergoing percutaneous transluminal coronary angioplasty (PTCA), infusion of hirudin (CGP 39393) was associated with higher and more stable aPTT measurements. ${ }^{1213}$ Preliminary evidence suggests that hirudin is a more effective anticoagulant than heparin in patients with unstable angina undergoing PTCA. The risk of early serious complications (death, myocardial infarction, or revascularisation) was about $40 \%$ less in the 759 patients treated with hirudin than in the 382 treated with heparin, ${ }^{13}$ though little difference was observed between the three regimens (two hirudin and one heparin regimen) at 6 months follow up. The risk of bleeding associated with the specific inhibitor seemed to be slight and the number of acute thrombotic complications small. Nevertheless, the efficacy and safety of the specific thrombin inhibitors should be assessed in larger trials and in more diverse clinical conditions. The concomitant administration of the thrombin inhibitors and thrombolytic agents needs careful consideration, and special attention should be given to the selection of the optimal dose under such circumstances. Initial experience with hirudin in combination with alteplase and with strep- 
Table 1 Intracranial haemorrhages in three recently published studies of heparin and hirudin combined with thrombolytic treatment

\begin{tabular}{lcc}
\hline Trial & Heparin $(n(\%))$ & Hirudin $(n(\%))$ \\
\hline GUSTO IIa & & \\
Alteplase & $4 / 436(0 \cdot 9)$ & $8 / 460(1 \cdot 7)$ \\
Streptokinase & $5 / 189(2 \cdot 7)$ & $6 / 189(3 \cdot 2)$ \\
Any thrombolytic * & $9 / 620(1 \cdot 5)$ & $14 / 644(2 \cdot 2)$ \\
TIMI 9A † & $7 / 368(1 \cdot 9)$ & $6 / 346(1 \cdot 7)$ \\
HIT-III $\ddagger$ & $1 / 154(0 \cdot 6)$ & $4 / 148(2 \cdot 7)$ \\
Total & $17 / 1142(1 \cdot 5)$ & $24 / 1137(2 \cdot 2)$ \\
\hline
\end{tabular}

* In GUSTO IIa 10 patients ( 5 heparin, 5 hirudin) received alteplase as well as streptokinase.

t In TIMI 9A $83 \%$ of patients received alteplase.

In TIMI $9 \mathrm{~A}$ 83\% of patients received altep

GUSTO, global use of strategies to open occluded coronary arteries; HIT, GUSTO, global use of strategies to open occluded coronary arteries; HIT,
$r$ hirudin for improvement of thrombolysis; TIMI, thrombolysis in myocardial infarction.

tokinase revealed no major safety issues. ${ }^{1415}$ However, in three subsequent larger studies an excess of major bleeding, in particular intracranial bleeds, was seen in patients treated with a high dose of hirudin combined with thrombolytic treatment (table 1). ${ }^{16-18}$ The overall rate of intracranial haemorrhage with hirudin was $2 \cdot 2 \%$. Other bleeding complications were also more frequent in patients receiving hirudin. Surprisingly, in two studies (GUSTO IIa and TIMI 9A) an unexpected excess of intracranial haemorrhage was also seen in patients receiving heparin in conjunction with thrombolytic treatment. This illustrates the narrow therapeutic range of combined thrombolytic and anticoagulant treatment. In fact, the heparin dosages in GUSTO IIa and TIMI 9A were only slightly higher than in previous studies. After extensive consultation two trials have been restarted-GUSTO IIb and TIMI 9B-both with a more prudent heparin regimen, and with a much lower dose of hirudin, which was reduced from a bolus of $0.6 \mathrm{mg} / \mathrm{kg}$ and an infusion of $0.2 \mathrm{mg} / \mathrm{kg} / \mathrm{h}$ to a bolus of $0.1 \mathrm{mg} / \mathrm{kg}$ followed by an infusion of $0.1 \mathrm{mg} / \mathrm{kg} / \mathrm{h}$. Another option might have been to reduce the dose of the thrombolytic agent, and further studies are needed to determine the optimal dosages for combination treatment in patients with evolving myocardial infarction.

If the results of ongoing trials with hirudin and with other thrombin inhibitors are favourable, it is likely that the specific inhibitors will replace heparin for many indications, provided that their costs are not prohibitive. The current generation of specific thrombin inhibitors must be given parenterally. It is, however, possible that synthetic thrombin inhibitors will be developed for oral use. This would open the possibility for long-term use for indications like those for the current coumadin type oral anticoagulants.

\section{IIb/IIIa receptor blockers}

Thrombocyte aggregation can be induced by many different stimuli, most commonly as a consequence of damage to the vessel wall. Platelets adhere to the vessel wall and are activated by the subendothelial tissue, notably collagen (figure), thereby inducing several coagulation reactions that result in thrombin generation, with the results described above. The final common pathway of platelet activation and aggregation is stimulation and activation of the thrombocyte glycoprotein (GP) IIb/IIIa receptor. ${ }^{19}$ This receptor complex consists of two interacting subunits, alpha and beta, belonging to the so-called integrin superfamily of adhesion receptors. ${ }^{20}$ Platelets aggregate as a result of (mainly) fibrinogen bridges between the IIb/IIIa receptors of adjacent thrombocytes. Several specific IIb/IIIa receptor blockers have been developed, including the chimeric 7E3 antibody (c7E3 Fab). ${ }^{21}$ Other inhibitors
Table 2 Outcome (\%) in EPIC with c7E3 Fab in 2099 patients undergoing "high risk" angioplasty

\begin{tabular}{lccc}
\hline & & $c 7 E 3$ Fab & $c 7 E 3$ Fab \\
& Placebo & bolus & bolus + IV \\
\hline Patients (n) & 696 & 695 & 708 \\
Balloon angioplasty & 90 & 90 & 90 \\
Atherectomy & 5 & 4 & 5 \\
Both & 5 & 6 & 5 \\
Major groin bleeding & $2 \cdot 8$ & $7 \cdot 0$ & $8 \cdot 1$ \\
Major other bleeding & $3 \cdot 7$ & $3 \cdot 9$ & $5 \cdot 8$ \\
Transusions: & $7 \cdot 0$ & 13 & 15 \\
Red cells & 3 & 4 & 6 \\
Platelets & & & \\
39 days: & $1 \cdot 7$ & $1 \cdot 3$ & $1 \cdot 7$ \\
Death & $8 \cdot 6$ & $6 \cdot 2$ & $5 \cdot 2$ \\
Non-fatal myocardial infarction & $3 \cdot 6$ & $2 \cdot 3$ & $2 \cdot 4$ \\
Emergency CABG & $4 \cdot 5$ & $3 \cdot 6$ & $0 \cdot 8$ \\
Emergency PTCA & $0 \cdot 6$ & $1 \cdot 7$ & $0 \cdot 6$ \\
Stent placement & & & \\
months: & $3 \cdot 4$ & $2 \cdot 6$ & $3 \cdot 1$ \\
Death & $10 \cdot 5$ & $8 \cdot 0$ & $6 \cdot 9$ \\
Non fatal myocardial infarction & $10 \cdot 9$ & $9 \cdot 9$ & $9 \cdot 4$ \\
CABG & $20 \cdot 9$ & $19 \cdot 9$ & $14 \cdot 4$ \\
Repeat PTCA & & \\
\hline
\end{tabular}

EPIC, Evaluation of 7E3 for Prevention of Ischaemic Complications.

of thrombocyte aggregation block different pathways in the thrombocytes. For example, aspirin blocks the arachidonic acid pathway and specific inhibitors of thromboxane synthesis and/or thromboxane receptors have also been developed. Aspirin is used widely as a mild inhibitor of thrombocyte aggregation, but clinical studies with thromboxane receptor blockers have been unsuccessful. ${ }^{22} 23$ In addition to the monoclonal antibodies to the IIb/IIIa receptor, smaller molecules including peptides (such as integrelin and MK-0852) and non-peptides (such as MK0383 and RO 44-9883) are also being investigated in clinical trials. ${ }^{24}$ These smaller molecules may be an advantage in the clinical environment, in that their action may be more readily reversible with little or no antigenicity.

So far, the monoclonal antibody c7E3 Fab has been tested most intensely, and its action has been studied in patients with refractory unstable angina, ${ }^{25}$ as well as during so-called high risk percutaneous transluminal coronary angioplasty. ${ }^{26}$ Sixty patients with angina at rest despite treatment with intravenous glyceryl trinitrate and heparin were randomised to (additional) c7E3 $\mathrm{Fab}$ or placebo given as a bolus injection followed by a 24 hour infusion before angioplasty. After treatment with c7E3 Fab binding of the free platelet receptor decreased sharply within a few hours, whereas platelet aggregation gradually recovered within 48 hours of the end of c7E3 infusion. Patients who were given c7E3 Fab were less likely to have recurrent ischaemia ( $9 v 16$ patients) and more likely to have successful PTCA procedure ( $17 \% v 30 \%$ failure). The risk of bleeding was similar in both groups (in 3 and 2 patients). ${ }^{25}$ In the much larger EPIC study, 2099 patients scheduled to undergo angioplasty and considered to be at high risk of abrupt vessel closure (and at low risk for bleeding) were given bolus of c7E3 Fab, a bolus and an infusion of c7E3 Fab, or placebo. ${ }^{26}$ Ischaemic complications associated with subsequent PTCA (chiefly non-fatal myocardial infarction and the need for emergency revascularisation) were reduced by $35 \%$ in the groups given c7E3, albeit against an increase in the risk of bleeding and a doubling of the transfusion rate (table 2). The efficacy of treatment persisted for 6 months. ${ }^{27}$ Ongoing trials must assess whether c7E3 and similar compounds will be as useful for other forms of arterial thrombosis including transient ischaemic attacks, stroke, and peripheral vascular disease.

The number of IIb/IIIa binding sites on the thrombocytes that are blocked and inhibition of platelet aggregation are affected by the dosage given. The current trials with c7E3 Fab aim at a dose that blocks more than $90 \%$ of 
the platelet binding sites. However, there is uncertainty about whether this represents the optimal dose. Perhaps different levels of inhibition of platelet aggregation are appropriate for different indications, but this remains to be established. Such individualised treatment would require monitoring of the level of blockage of IIb/IIIa receptors, but currently there are no methods for such monitoring.

Presently, IIb/IIIa receptor blockers are available for intravenous use only, and their use is therefore restricted to patients in hospital. Oral compounds are being developed. If these were successful, they might replace aspirin for the long-term treatment of coronary artery disease, provided that they did not cost too much.

\section{Combined application}

Potentiation between thrombin inhibitors and IIb/IIIa receptor blockers has been seen in animal experiments. ${ }^{28}$ A combination of these compounds may become the preferred treatment. Similarly, in animal experiments thrombolysis was enhanced by addition of a IIb/IIIa receptor blocker to thrombocyte agents. ${ }^{29}$ Because such combinations could induce excessive bleeding careful studies are needed to determine the optimal dose combinations of these drugs for various groups of patients.

Different types of patients may need different approaches. In particular decisions on the level of anticoagulation or a decision to combine specific antithrombins with the IIb/IIIa receptor blockers might be based on the expected thrombotic risk in each patient.

\section{Myocardial infarction}

The risk of mortality and other complications in patients with myocardial infarction can be estimated from baseline characteristics including elderly age, a history of previous infarction, a large area at risk, and the presence of heart failure. Both the short and long-term benefits of thrombolytic treatment are directly proportional to the level of the baseline risk. ${ }^{30}$ Thus more intense treatment may be warranted in patients at a higher risk of mortality. In such patients, a combination of thrombolytic treatment with specific thrombin inhibitors and IIb/IIIa receptor blocker may be appropriate, even if such combination carries a higher bleeding risk. On the other hand, in subgroups of patients at low risk in whom the benefit of treatment is expected to be small, bleeding risk should be reduced and the mode and intensity of anticoagulant treatment should be adapted accordingly.

\section{Unstable angina}

Patients with unstable angina are at an increased risk of myocardial infarction and death. The term "unstable angina", however, encompasses a wide range of disease with different levels of risks. The risk of complications is often over-rated, however. In 15 observational studies and randomised trials conducted in the 1970 s and 1980s, before intravenous glyceryl trinitrate, heparin, and aspirin were widely used, average mortality was only $2 \%$ at one month and $6 \%$ at 6 months. ${ }^{31}$ In a more recent prospective registry of 282 patients with documented unstable angina (pain and electrocardiographic changes in hospital), non-fatal myocardial infarction developed in only $10 \%$ of the patients. ${ }^{31}$ Similarly, less than $10 \%$ of patients in the ATACS trial died or had non-fatal infarction. ${ }^{32}$

In patients with unstable angina, in particular those at highest risk (for instance in patients with a recent $(<24$ hours) episode of ischaemia or in patients whose symp- toms persist despite treatment) anticoagulant treatment should be intensive and be continued until the ruptured plaque has healed, ideally for 3-7 days.

Patients with unstable angina are likely candidates for intervention. The risk of complications during PTCA and other coronary interventions is related to the clinical presentation of the patient as well as to the angiographic appearance of the coronary lesion. Again, more intensive treatment will be warranted in patients with unstable angina, and antithrombotic and anticoagulant treatment can be increased if thrombotic complications are seen during or after the procedure.

\section{Chronic ambulatory treatment}

Most patients in whom coronary artery disease has been diagnosed, particularly those with angina and survivors of myocardial infarction, are currently treated with aspirin. Although indirect evidence suggests that the coumadin agents may be more effective, at least in myocardial infarction survivors, ${ }^{33}$ most clinicians favour the much cheaper and easier to use thrombocyte aggregation inhibitor. As specific oral thrombin inhibitors and/or specific receptor blockers become available, these may be prescribed to prevent thrombotic complications in these patients, and also after cardiac surgery and in those with atrial fibrillation, deep venous thrombosis, pulmonary embolism, and after vascular surgery. Again, the intensity of treatment could be tailored to the expected rate of thrombotic complications. More intensive treatment could be given in the first months after myocardial infarction or shortly after a period of unstable angina. Cigarette smoking, associated with activated coagulation, could also be considered as an indication for more intense coagulation. Treatment could be less intense in other circumstances, for instance during the first 6 months after an acute ischaemic event, and in elderly patients, who are at greater risk of bleeding complications.

\section{Conclusions}

The specific thrombin inhibitors and platelet IIb/IIIa receptor blockers that are currently being tested in clinical trials promise to provide better treatment for a wide range of patients at increased risk of thrombosis. Combination therapy may be appropriate, particularly when there are thrombotic complications, or in patients at greatest risk of complications. The most effective methods of monitoring the effect of these new treatments remain to be defined.

MAARTEN L SIMOONS

Thoraxcenter, Department of Cardiology JAAP W DECKERS

Erasmus University and University Hospital "Dijkzigt"

Dr Molewaterplein 40

3015 GD Rotterdam

The Netherlands

We thank Jean-Paul R Herrman for preparing the figure.

1 Badimon L, Badimon J, Fuster V. Pathogenesis of thrombosis. In: V Fuster, M Verstraete, eds. Thrombosis in cardiovascular disorders. Philadelphia: WB Saunders, 1992;17-39.

2 Chesebro JH, Fuster V. Dynamic thrombosis and thrombolysis. Role of antithrombins. Circulation 1991;83:1815-7.

3 Krupinsky K, Breddin HK, Markwardt F, Haarmann W. Antithrombotic effects of three thrombin inhibitors in a rat model of laser-induced thrombosis. Haemostasis 1989;19:74-82.

4 Deutsch E, Koneti Roa A, Colman RW. Selective thrombin inhibitors: The next generation of anticoagulants. $\mathcal{F}$ Am Coll Cardiol 1993;22:1089-92.

5 Simoons ML, Miltenburg A van, Scheffer MG, et al. Anticoagulant properties of efegatran, a direct thrombin inhibitor in patients with unstable angina [abstr]. Eur Heart $\mathcal{F}$ 1994;15:120.

6 Hirsch J. Heparin. N Engl f Med 1991;324:1565-74.

7 Verstraete M, Nurmohamed M, Kienast J, Siebeck M, Silling-Engelhardt G, Büller H, et al for the European Hirudin in Thrombosis Group. Biologic effects of recombinant hirudin (CGP 39393) in human volunteers. F Am Coll Cardiol 1993;22:1080-8. 
8 Cannon CP, Maraganore JM, Loscalzo J, McAllister A, Eddings K, George $\mathrm{D}$, et al. Anticoagulant effects of hirulog, a novel thrombin inhibitor, in patients with coronary artery disease. Am $\mathcal{F}$ Cardiol 1993;71:778-82.

9 Zoldhelyi P, Webster MWI, Fuster V, Grill DE, Gasper D, Edwards SJ, et al. Recombinant hirudin in patients with chronic, stable coronary artery disease. Safety, half-life, and effect on coagulation parameters. Circulation 1993;88:2015-22.

10 Lidón RM, Théroux P, Juneau M, Adelman B, Maraganore J. Initial experience with a direct antithrombin, hirulog, in unstable angina Anticoagulant, antithrombotic, and clinical effects. Circulation 1993;88: 1495-501.

11 Topol EJ, Clarke RJ, Mayo G, Fitzgerald GA, Fitzgerald DJ. Combined administration of aspirin and a specific thrombin inhibitor in man Circulation 1993;87:1622-9.

12 Bos A van de, Deckers JW, Heyndrickx GR, Laarman GH, Suryapranata $\mathrm{H}, \mathrm{Zijlstra} \mathrm{F}$, et al. Safety and efficacy of recombinant hirudin (CGP 39 393) versus heparin in patients with stable angina undergoing coronary angioplasty. Circulation 1993;88:2058-66.

13 Serruys PW, Deckers JW, Close P. A double blind, randomized, heparin controlled trial evaluating acute and longterm efficacy of r-hirudin (CGP 39393 ) in patients undergoing coronary angioplasty [abstr]. Circulation 1994;90:I-394.

14 Cannon CP, McCabe CH, Henry TD, Schweiger MJ, Gibson RS, Mueller HS, et al. A pilot trial of recombinant desulphatohirudin compared with heparin in conjunction with tissue-type plasminogen activator and aspirin for acute myocardial infarction: results of the Thrombolysis in Myocardial Infarction (TIMI) 5 trial. $\mathcal{f} \mathrm{Am}$ Coll Cardiol 1994;23: 933-1003.

15 Lee LV, McCabe CH, Antman EM, Koch M, Wilensky R, Stringer K et al, for the TIMI 6 Investigators. Initial experience with hirudin and strepfor the TIMI 6 Investigators. Initial experience with hirudin and strep[abstr]. $7 \mathrm{Am}$ Coll Cardiol 1994;23:344A

16 Antman EM, for the TIMI 9A Investigators. Hirudin in acute myocardial infarction. Safety report from the thrombolysis and thrombin inhibition in myocardial infarction (TIMI) $9 \mathrm{~A}$ trial. Circulation 1994;90:1624-30.

17 The Global Use of Strategies to Open Occluded Coronary Arteries (GUSTO) II a Investigators. Randomized trial of intravenous heparin versus recombinant hirudin for acute coronary syndromes. Circulation 1994;90:1631-7.

18 Neuhaus KL, Essen R v, Tebbe U, Jessel A, Heinrichs H, Mäurer W, et al. Safety observations from the pilot phase of the randomized r-hirudin for improvement of thrombolysis (HIT-III) study. A study of the Arbeitsgemeinschaft Leitender Kardiologischer Krankenhausärzte (ALKK). Circulation 1994;90:1638-42.

19 Coller BS. Platelets and thrombolytic therapy. $N$ Engl f Med 1990;322: $33-42$.

20 Albelda SM, Buck CA. Integrins and other cell adhesion molecules. FASEB 7 1990;4:2868-80.

21 Coller BS, Folts JD, Smith SR, Scudder LE, Jordan R. Abolition of in vivo platelet thrombus formation in primates with monoclonal antibodies to the platelet GPIIb/IIIA receptor. Correlation with bleeding time, platele aggregation, and blockade of GPIIb/IIIa receptors. Circulation 1989; 80:1766-74

22 Serruys PW, Rutsch W, Heyndrickx GR, Danchin N, Mast G, Wijns W. et al for the Coronary Artery Restenosis Prevention of Repeated Thromboxane-Antigonism Study Group (Carport). Prevention of restenosis after percutaneous transluminal coronary angioplasty with thromboxane A -receptor blockade. A randomized, double-blind, placebo-controlled trial. Circulation 1991;84:1568-80.

23 The RAPT Investigators. Randomized trial of ridogrel, a combined thromboxane $A_{2}$ synthase inhibitor and thromboxane $A_{2} /$ prostaglandin boxane $\mathrm{A}_{2}$ synthase inhibitor and thromboxane $\mathrm{A}_{2}$ /prostaglandin ysis in patients with acute myocardial infarction. The ridogrel versus ysis in patients with acute myocardial infarction. The

24 Gould RJ. The integrin $\alpha_{\mathrm{II}} \beta_{3}$ as an antithrombotic target. Perspectives in drug discovery and design. 1995 (in press).

25 Simoons ML, Boer MJ de, Brand MJBM vd, Miltenburg AJM v, Hoorntie JCA, Heyndrickx GR, et al, and the European Cooperative Study Group. Randomized trial of a GPIIb/IIIa platelet receptor blocker in refractor unstable angina. Circulation 1994;89:596-603.

26 The EPIC Investigators. Use of a monoclonal antibody directed against the platelet glycoprotein IIb/IIIa receptor in high-risk coronary angioplasty. N Engl f Med 1994;330:956-61.

27 Topol EJ, Califf RM, Weisman HF, Ellis SG, Tcheng JE, Worley S, et al, on behalf of The EPIC Investigators. Randomised trial of coronary intervention with antibody against platelet IIb/IIIa integrin for reduction of clinical restenosis: results at six months. Lancet 1994;343:881-6.

28 Yasuda T, Gold HK, Yaoita H, Leinbach RC, Guerrero JL, Jang I-K, et al. Comparative effects of aspirin, a synthetic thrombin inhibitor and a monComparative effects of aspirin, a synthetic thrombin inhibitor and a monreperfusion, reocclusion and bleeding with recombinant tissue-type plasreperfusion, reocclusion and bleeding with recombinant tissue-type plasminogen actir

29 Gold HK, Coller BS, Yasuda T, Saito T, Fallon JT, Guerrero JH, et al. Rapid and sustained coronary artery recanalization with combined bolus injection of recombinant tissue-type plasminogen activator and monoclonal antiplatelet GPIIb/IIIa antibody in a canine preparation. Circulation 1988;3:670-7.

30 Simoons ML, Arnold AER. Tailored thrombolytic therapy. Circulation 1993;88:2256-64.

31 Miltenburg-van Zijl AJM. Management policies and prognosis in unstable angina pectoris. Use of coronary angiography in different practice settings. Erasmus University Rotterdam. Thesis 1992 .

32 Cohen M, Adams PC, Parry G, and the Antithrombotic Therapy in Acute Coronary Syndromes Research Group. Combination antithrombotic therapy in unstable rest angina and non-Q-wave infarction in non prior therapy in unstable rest angina and non- $Q$-wave infarction in non prio
aspirin users. Primary end points analysis from the ATACS trial. Circulation 1994;89:81-8.

33 The Aspect Study Group. The effect of long-term therapy with oral anticoagulants on mortality and cardiovascular morbidity after myocardial infarction. Lancet 1994;343:499-503. 